\title{
Artiflex foldable lens for myopia correction results of 10 years of follow-up
}

\author{
Gracia Castro de Luna $\mathbb{i}^{1} \cdot$ Darío Ramos-López ${ }^{2} \cdot$ Ana Belén Castaño Fernández $\mathbb{B}^{3}$ - Diego Cuevas Santamaría ${ }^{4}$
}

Received: 18 September 2018 / Revised: 8 April 2019 / Accepted: 11 April 2019 / Published online: 29 April 2019

(c) The Royal College of Ophthalmologists 2019

\begin{abstract}
Purpose The aim of this study was to evaluate the long-term efficacy and safety of the Artiflex ${ }^{\circledR}$ lens implant and to follow the evolution of the number of corneal endothelial cells over time.

Design It was a retrospective study of an observational case series of patients who underwent surgery at "The INVISION Ophthalmic Hospital" (Almería, Spain) in 2007 and who were followed for 10 years.

Methods Setting: Clinical practice. Study population included 53 eyes of 30 patients who underwent an Artiflex ${ }^{\circledR}$ lens implant for the correction of myopia from -4 to $-14 \mathrm{D}$. Each patient included in this study had stable myopia for at least 2 years and a contraindication for corneal refractive surgery. The efficacy index was defined as the quotient between uncorrected distance visual acuity postoperative and best-corrected distance visual acuity (BCDVA) preoperative. The safety index was calculated as the quotient between BCDVA postop and BCDVA preop.

Results The average efficacy and safety indices of the lenses implanted were 1.1 (SD 0.30) and 1.06 (SD 0.2) at 10 years of follow-up. In this period of time there has been a loss of $12 \%$ of the corneal endothelial cells. The postoperative complications were pigment dispersion in four eyes $(7 \%)$ of four patients and decentration of phakic intraocular lens in two eyes $(4 \%)$ of another two patients.

Conclusions The Artiflex $^{\circledast}$ foldable phakic lens could be a safe and effective long-term alternative for myopic patients in whom laser surgery was contraindicated.
\end{abstract}

\section{Introduction}

The main objective of refractive surgery is to improve the quality of life of patients by reducing their dependence on glasses and contact lenses. In the past years, corneal surgery with Excimer laser has become the standard for correcting a wide range of refractive errors with usually good results [1].

$\triangle$ Gracia Castro de Luna

graciacl@ual.es

1 Department of Nursing, Physiotherapy and Medicine, University of Almería, Almería, Spain

2 Department of Applied Mathematics, Materials Science and Engineering and Electronic Technology, Rey Juan Carlos University, Móstoles, Spain

3 Department of Mathematics, University of Almería, Almería, Spain

4 Department of Refractive Surgery, INVISION Ophthalmologic Hospital, Almería, Spain
For patients not suitable for corneal surgery, the implantation of a phakic intraocular lens (pIOL) can be a good alternative [2]. Currently, there are two types of pIOL: anterior chamber phakic lens and posterior chamber phakic lens. Phakic anterior chamber lenses can be rigid polymethylmethacrylate (PMMA) or a foldable version where the optic is made of polysulfone and has two opposite haptics of PMMA that allows the fixation to the periphery of the iris [3,4]. This folding phakic lens can be inserted or eliminated through a small corneal incision without sutures. The advantages of anterior chamber phakic lenses are the preservation of the corneal tissue eliminating the risk of ectasia, maintenance of the corneal topography without inducing high-order aberrations, and the possibility of removal [5]. The anterior chamber phakic lens fixed to the iris can be centered on the pupil, which is very important in the eyes with a decentration. Another advantage of this lens is that the tear film is preserved [5]. The main disadvantages of iris-fixed lenses are the difficulty of implantation, and the potential damage to the iris and the corneal endothelium [6]. Other possible postoperative complications described are 
endophthalmitis, elevated intraocular pressure, subclinical inflammation, corneal decompensation, dislocation of pIOL, cataract formation, retinal detachment, ovalization of the pupil, and pigment dispersion [7-10]. Several studies have demonstrated the safety, efficacy, and high predictability of the implantation of pIOLs [11-13], but there are no articles publishing 10 -year results.

\section{Patients and methods}

It was a retrospective study of an observational case series of patients that included 53 eyes of 30 patients who underwent of an Artiflex ${ }^{\circledR}$ lens implant for the correction of myopia from -4 to $-14 \mathrm{D}$ with an spherical equivalent (SE) of $-9.97 \mathrm{D}$ (3.55). They were all patients in the refractive surgery department of "The INVISION Ophthalmologic Hospital (Almeria, Spain). The lenses were implanted during 2007 and followed until 2017. Each patient included in this study had stable myopia for at least 2 years and contraindications to corneal surgery, mainly irregular corneal topography and not enough corneal thickness for corneal surgery. In addition, the following preoperative conditions must be met: anterior chamber depth (ACD) $\geq 3.4 \mathrm{~mm}$, the EC count $\geq 2500$ cells/ $\mathrm{mm}^{2}$, diameter of the mesopic pupil $\leq 6.5 \mathrm{~mm}$, and astigmatism $\leq 2.0 \mathrm{D}$. The exclusion criteria were: patients under 21 years of age, active pathology of the eye, such as cataract, glaucoma, and chronic recurrent uveitis, previous surgical procedure, macular and retinal pathology, systemic autoimmune diseases, diabetes, and pregnancy. The principles followed the Helsinki agreement; all patients signed an informed consent form and were provided with a copy of it. The preoperative examination included uncorrected distance visual acuity (UCDVA), best-corrected distance visual acuity (BCDVA) (decimal fraction, Snellen scale) [14], refractive using autorefractometer (Nidek ARK- 700, Japan), IOP (Noncontact tonometer, Reichert Inc., Buffalo, NY, USA), biomicroscopic examination (HaagStrait BQ 900 Swiss), pachymetry ((DGH 500, DGH Technology Inc., Exton, PA, USA) fundus examination, corneal topography (CSO, Oftaltech, CM02 Italy), CE count (SP-2000, Topcon, Japan)), and size of pupil (Pupilographer, Florence, Italy). Phakic IOL calculations were based on nomograms or software developed by the manufacturers (Ophtec, Netherlands) that require refractive error, corneal curvature, and $\mathrm{ACD}$ aiming at emmetropia. When the lens calculated to obtain the emmetropia was not available (due to steps $0.50 \mathrm{D}$ in lenses), a slight myopia was preferred. The corneal incision was $3.2 \mathrm{~mm}$ at twelve o'clock. Two vertical paracenteses were performed at two and ten o'clock. After the intracameral injection of acetylcholine and viscoelastic material, the pIOL (Artiflex ${ }^{\circledast}$, Ophthec) was implanted in the anterior chamber. The phakic intraocular lens was fixed with a locking needle in the three o'clock position and nine o'clock in the iris. Subsequently, the viscoelastic material was removed and the hydration of the corneal incision for its sealing. A postoperative revision was made on days 1 and 7 and UCDVA, IOP, and biomicroscopy were recorded. In other test intervals (3 months, 1, 2, 5, and 10 years), a complete examination was performed, which included UCDVA, BCDVA, IOP, SE, EC count, biomicroscopy (slit-lamp examination), and ophthalmoscopy. The efficacy index [15] was defined as the quotient between UCDVA postoperative and BCDVA preoperative. The safety index [15] was calculated as the quotient between BCDVA postop and BCDVA preop. Statistical analysis was performed using SPSS for Windows software (version 17.0, SPSS Inc.). The Kolmogorov-Smirnov test was applied for all data samples to check for normality. The Kolmogorov-Smirnov test was applied for all data samples to check for normality. When parametric statistical analysis was possible, the Student's test for paired data was applied to assess the significance of differences between preoperative data and postoperative data, whereas the Wilcoxon's signedrank test was used when the parametric analysis was not possible. The level of statistical significance was $p<0.05$

\section{Results}

We analyzed 53 eyes of 30 patients who underwent an Artiflex ${ }^{\circledR}$-type lens implant, of them 23 underwent bilateral surgery (46 eyes) and 7 monolateral ones. Forty percent (12/ $30)$ were men and $60 \%(18 / 30)$ were women. For all variables, the arithmetic average and the standard deviation (between parentheses) were calculated. The average age was 33.4 (6.45) years. The average BCDVA was 0.63 (0.15). Preoperative patient characteristics are detailed in Table 1. The power of the Artiflex ${ }^{\circledR}$ lens was -10.88 (2.90). The number of operated eyes considered in each time period is specified on the abscissa axiss, between parentheses (Fig. 1). There was a statistically significant progression of the UCDVA from the first month until reaching a maximum at 2 years, then there was no statistically significant change at 5 and 10 years, respectively, which indicated a stability of the UCDVA achieved (Fig. 1a). The BCDVA also reached

Table 1 Preoperative characteristics

\begin{tabular}{ll}
\hline & Mean $(\mathrm{SD})$ \\
\hline Number of eyes & 53 \\
Sphere $(\mathrm{D})$ & $-9.97(3.55)$ \\
Cylinder $(\mathrm{D})$ & $-1.53(1.11)$ \\
EC $\left(\right.$ cells $\left./ \mathrm{mm}^{2}\right)$ & $3107.13(427.71)$ \\
Axial length $(\mathrm{mm})$ & $27.47(1.72)$ \\
Pachymetry $(\mu \mathrm{m})$ & $508(36)$ \\
\hline
\end{tabular}




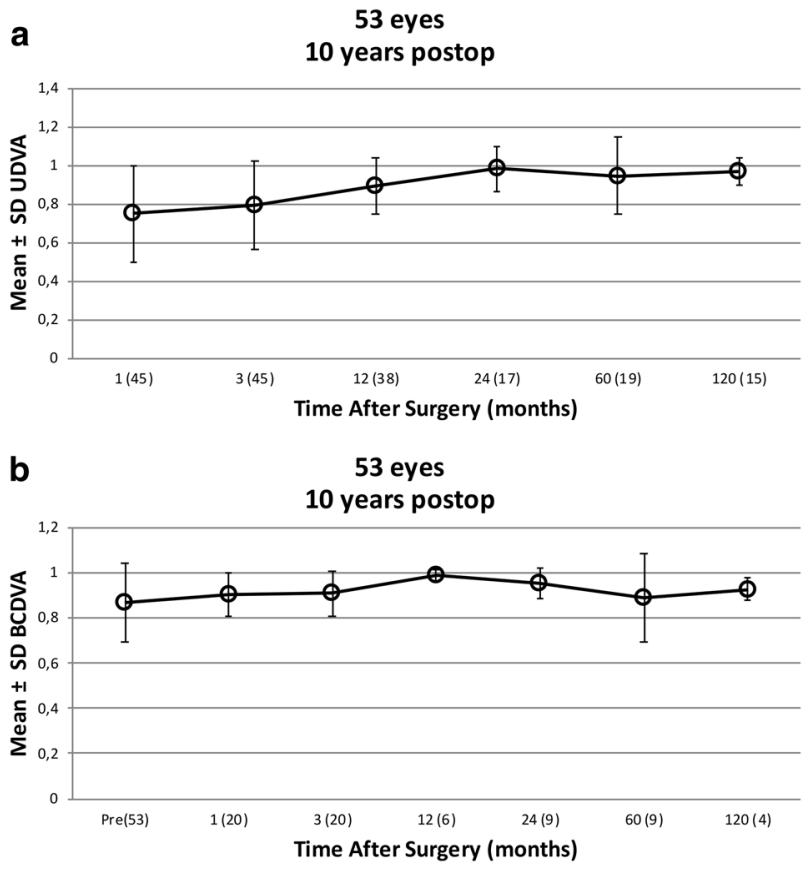

Fig. 1 a Uncorrected distance visual acuity (UCDVA) time after surgery (months). b Corrected distance visual acuity (CDVA) time after surgery (months)

Table 2 Comparison of the averages of BCDVA (SD) over time

\begin{tabular}{lc}
\hline Pre & $0.87(0.17)$ \\
Post 1 month & $0.91(0.10)$ \\
Post 3 months & $0.91(0.10)$ \\
Post 1 year & $0.99(0.02)^{\mathrm{a}}$ \\
Post 2 years & $0.95(0.07)$ \\
Post 5 years & $0.89(0.20)$ \\
Post 10 years & $0.92(0.05)$ \\
\hline
\end{tabular}

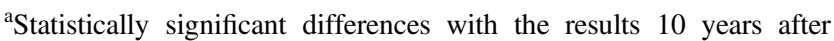
surgery

its maximum value after 2 years and remained stable until 10 years (Fig. 1b). Table 2 shows an improvement in the BCDVA at 10 years compared to that presented by the patient in the preoperative period, although it was not statistically significant.

The average efficacy index was 1.01 (0.43) after 1 month, reached a maximum $(1.24(0.41))$ after 2 years, and stabilized $(1.1(0.30))$ after 5 and 10 years after surgery. The average security index was $1.04(0.27), 1.16(0.4), 1.1$ (0.15), $1.02(0.1), 0.96(0.21), 1.06(0.2)$ after 1 month, 3 months, and 1, 2, 5, and 10 years, respectively. Figure $2 \mathrm{a}-\mathrm{d}$ shows the percentage of accumulated vision lines for each follow-up period. The UCDVA was $\geq 20 / 25$ in $89 \%, \geq 20 / 20$ in $68 \%$ of the eyes after 5 years of follow-up, and $\geq 20 / 25$ in $100 \%$ and $\geq 20 / 20$ in $80 \%$ of the eyes after 10 years of surgery. Table 3 shows that there is a statistically significant improvement in the UCDVA at 10 years compared to that presented by the patient in the first year after surgery.

The mean of SE was $-0.39(0.31) \mathrm{D}$ after a year. SE values increased to $-1.19(1.23) \mathrm{D}$ after 5 years of surgery reaching a maximum at 10 years $(-1.75(0.05) \mathrm{D})$ (Fig. 3a). Table 4 shows that the SE at 10 years differs statistically from that observed in the first year.

Figure $3 \mathrm{~b}$ shows the evolution of the average and standard deviation of corneal endothelial cell count over time. There is a statistically significant loss of endothelial cells from the first month to the tenth year (Table 5). An estimated $13.97 \%$ of the cells were lost 10 years after surgery, although the number of endothelial cells was sufficient to not remove the lenses. The postoperative complications were pigment dispersion in four eyes (7\%) of four patients and decentration of pIOL in two eyes (4\%) of another two patients.

\section{Discussion}

In this study, the visual acuity and changes in SE and endothelial cells before and after Artiflex $^{\circledR}$ lens implant were evaluated. The Artiflex ${ }^{\circledast}$ lens surgery has been considered as an appropriate alternative to glasses and contact lens, especially in patients younger than 40 years with a high myopia and for patients not suitable for corneal surgery. The aim of our work has been to evaluate the efficacy and safety of this lens implantation followed over 10 years. According to our results, there was a progression of the UCDVA and the BCDVA from the first month until reaching a maximum at 2 years, then there was no statistically significant change at 5 and 10 years, respectively (Fig. 1a, b). In a 2015 retrospective study with 158 eyes comparing results at 6 months, 1 year, and 2 years, Aerts et al. [13] obtained a higher UCDVA than 20/25 at 1 year and 2 years of follow-up in $95 \%$ of the cases. In our study, we obtained at 2 years an UCDVA $\geq 20 / 25$ in $94 \%$ of the eyes, and $\geq 20 / 20$ in $71 \%$ of the eyes (Fig. 2b) Ghoreishi et al. $[16,17]$ in 2014 in a prospective non-randomized study of 31 eyes of 18 patients starting from an initial SE of -9.58 (1.92) obtained an UCDVA equal to or better than $20 / 20$ in $45 \%$ of the cases after a follow-up of 6 months; $83.8 \%$ of the eyes gained a line or more after surgery. Doors et al. [18] in 2012 published the results of the multicentric European prospective study of 115 eyes of 73 patients, followed 6 months with an initial SE of -7.10 (2.70), which were obtained in $99 \%$ of patients, with the UCDVA $>20 / 40$ in $74.5 \%$. Nassiri et al. [19] in 2018 in a retrospective study of 55 eyes of 29 patients followed 6 months, the UCDVA was $20 / 25$ or better in $81.5 \%$ of the cases. The results of Hashemi et al. $[20,21]$ in a study with 53 eyes of 28 patients with sphere $-10.22 \pm(3.02)$ were that $72.2 \%$ of the eyes had 20/25 or more vision and the safety and efficacy 

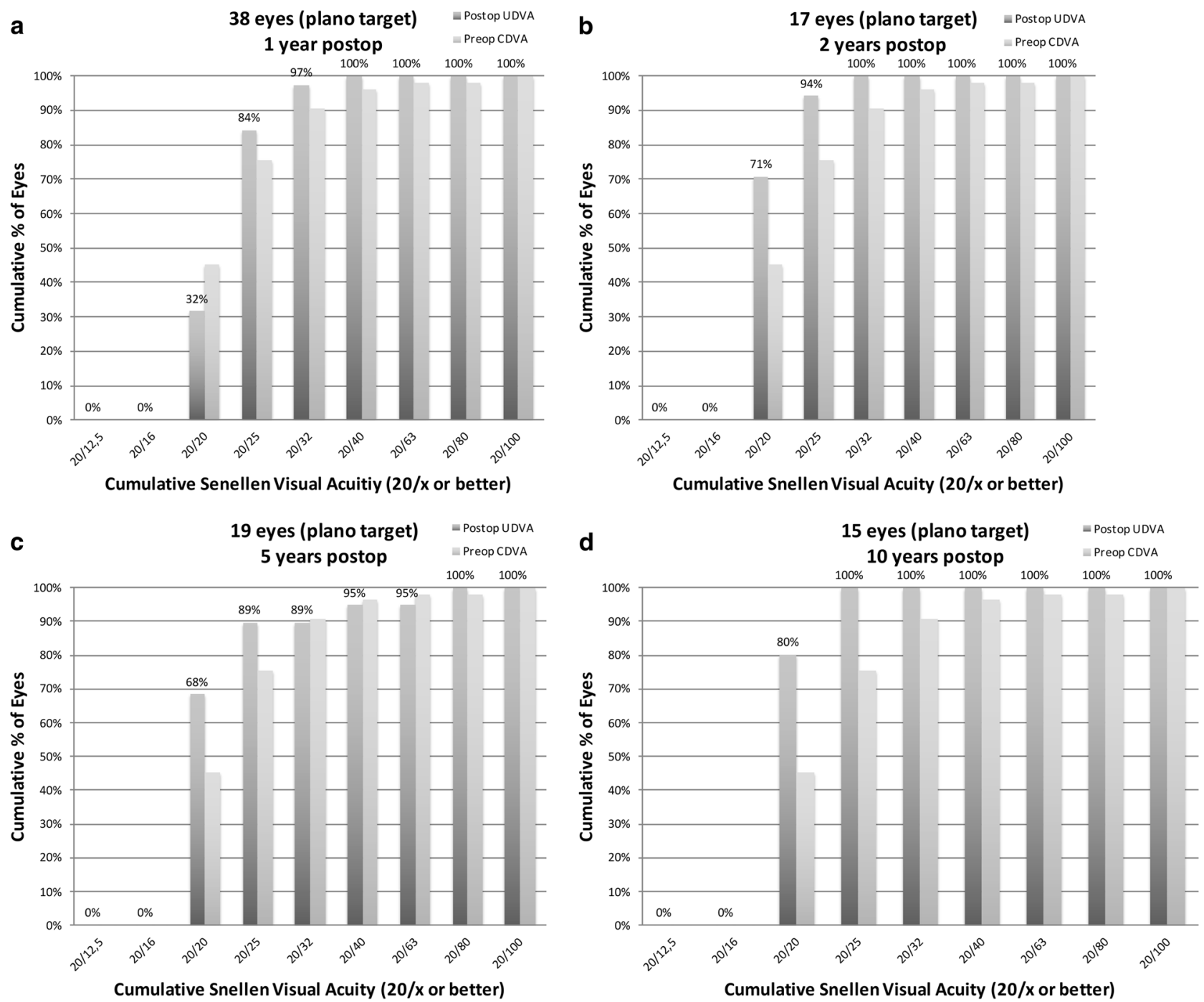

Fig. 2 a Cumulative Snellen visual acuity 1 year after surgery. b Cumulative Snellen visual acuity 2 years after surgery. c Cumulative Snellen visual acuity 5 years after surgery. d Cumulative Snellen visual acuity 10 years after surgery

Table 3 Comparison of the averages of UCDVA (SD) over time

\begin{tabular}{ll}
\hline Post 1 month & $0.75(0.25)^{\mathrm{a}}$ \\
Post 3 months & $0.79(0.23)^{\mathrm{a}}$ \\
Post 1 year & $0.89(0.14)$ \\
Post 2 years & $0.98(0.11)$ \\
Post 5 years & $0.94(0.20)$ \\
Post 10 years & $0.96(0.07)$ \\
\hline
\end{tabular}

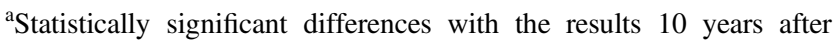
surgery

were 1.16 and 1.05 per year. In our study, the efficacy index was increased from $1.01(0.43)$ at 1 month, $1.07(0.36)$ at 3 months, $1.11(0.43)$ after 1 year, $1.24(0.41)$ after 2 years, to $1.1(0.30)$ after 5 years and 10 years. The safety index was increased from $1.04(0.27)$ at 1 month to $1.06(0.2)$ after
10 years. Ruckhofer et al. [22] in a retrospective study in 2012 of 42 eyes of 24 patients with a preoperative SE of -7.52 (2.22) obtained results at 6 months postop of $90 \%$ of the eyes with $\geq 20 / 20$ of UCDVA. Finally, Dick et al. [23] in 2009 in a 2-year multicenter prospective study with 190 eyes of 191 patients and a preoperative SE of -7.33 (2.60) achieved a UCDVA $\geq 20 / 40$ in $97.2 \%$ of the cases after 2 years . The loss of endothelial cells was $1.07 \%$ at 2 years. In other studies, the results of UCDVA [24-27] are coincident with our work, especially in the first and second year. According to the results of our study, the endothelial cell losses in percentages were similar to those obtained by the different authors after 2 years of follow-up [24-28]. In conclusion, our findings showed that the patients operated with an Artiflex $^{\circledR}$ phakic lens implant maintained their BCDVA and UCDVA over time. The results reported that 

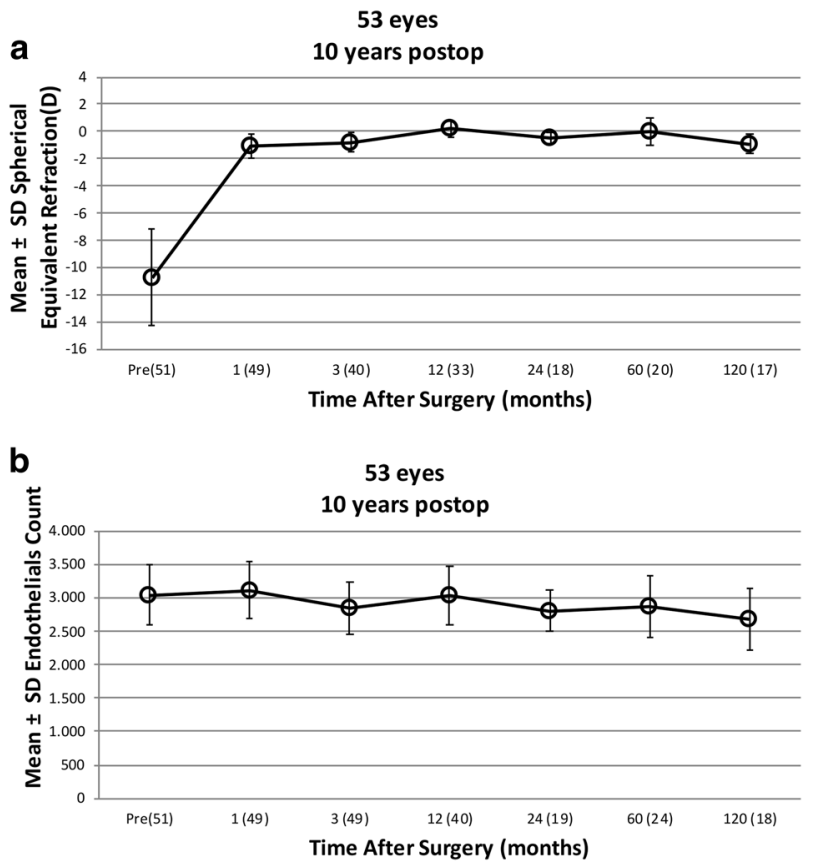

Fig. 3 a Spherical equivalent refraction time after surgery (months). b Endothelial cell count time after surgery (months)

Table 4 Comparison of the averages of SE (SD) over time

\begin{tabular}{lr} 
Post 1 month & $-1.09(0.85)$ \\
Post 3 months & $-0.82(0.65)$ \\
Post 1 year & $0.17(0.79)^{\mathrm{a}}$ \\
Post 2 years & $-0.48(0.48)^{\mathrm{a}}$ \\
Post 5 years & $0.02(1.21)^{\mathrm{a}}$ \\
Post 10 years & $-0.90(0.85)$ \\
\hline
\end{tabular}

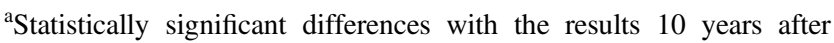
surgery

Table 5 Comparison of the averages of endothelial cell count (SD) over time

\begin{tabular}{ll}
\hline Post 1 month & $3107.29(427.71)^{\mathrm{a}}$ \\
Post 3 months & $2848.51(389.27)$ \\
Post 1 year & $3028.17(436.03)^{\mathrm{a}}$ \\
Post 2 years & $2804.10(301.39)$ \\
Post 5 years & $2866.62(459.62)$ \\
Post 10 years & $2673.44(452.65)$
\end{tabular}

${ }^{\text {a }}$ Statistically significant differences with the results 10 years after surgery

endothelial cell loss was $<10 \%$ after 10 years. It could be proposed as a good alternative when laser surgery is contraindicated; however, it is necessary to continue increasing the number of patients analyzed up to 10 years to corroborate these results.

\section{Summary}

\section{What was known before}

- There are very few studies on the safety and efficacy of the implantation of phakic lenses of anterior camera type iris claw in the long term.

\section{What this study adds}

- The article contributes to demonstrate the efficacy and safety of the phakic lenses of anterior camera type iris claw as the artiflex in the correction of myopia.

Funding DR-L and $\mathrm{ABCF}$ thank the support from CDTIME, the research group FQM-229, and from the Campus de Excelencia Internacional del Mar (CEIMAR) of the University of Almería.

Author contributions Design of the study: GCdL, DCS; collection of the data: GCdL. Analysis and interpretation of the data: DR-L, ABCF. Writing—original draft preparation: GCdL, DR-L.

\section{Compliance with ethical standards}

Conflict of interest The authors declare that they have no conflict of interest.

Ethical approval All procedures performed in studies involving human participants were in accordance with the ethical standards of the institutional and national research committee and with the Declaration of Helsinki and its later amendments or comparable ethical standards.

Informed consent Informed consent was obtained from all individual participants included in the study.

Statement about conformity The study was approved by the institutional review board and followed the tenets of Declaration of Helsinki.

Publisher's note: Springer Nature remains neutral with regard to jurisdictional claims in published maps and institutional affiliations.

\section{References}

1. Chaudhry IA, El Danasoury MA. Phakic intraocular lenses. Saudi J Ophthalmol. 2013;27:31.

2. Lackner B, Pieh S, Schmidinger G, Hanselmayer G, Dejaco-Ruhswurm I, Funovics MA. et al. Outcome after treatment of ametropia with implantable contact lenses. Ophthalmology. 2003;110:2153-61.

3. Health Quality Ontario. Phakic intraocular lenses for the treatment of refractive errors: an evidence-based analysis. Ont Health Technol Assess Ser. 2009;9:1-120.

4. Barsam A, Allan BDS. Excimer laser refractive surgery versus phakic intraocular lenses for the correction of moderate to high myopia. Cochrane Database Syst Rev. 2014;6:CD007679. https:// doi.org/10.1002/14651858.CD007679.pub4. 
5. El Danasoury MA, El Maghraby A, Gamali TO. Comparison of iris-fixed Artisan lens implantation with excimer laser in situ keratomileusis in correcting myopia between -9.00 and -19.50 diopters: a randomized study. Ophthalmology. 2002;109:955-64.

6. Guell JL, Morrel M, Kook D, Kohnen T. Phakic intraocular lenses. Part 1: historical overview, current models, selection criteria and surgical techniques. J Cataract Refract Surg. 2010;36:1976-93.

7. Patel SR, Chu DS, Ayres BD, Hersh PS. Corneal edema and penetrating keratoplasty after anterior chamber phakic intraocular lens implantation. J Cataract Refract Surg. 2005;31:2212-5.

8. Stulting RD, John ME, Maloney RK, Assil KK, Arrowsmith PN, Thompson VM. Three-year results of Artisan/Verisyse phakic intraocular lens implantation. Ophthalmology. 2008;115:464-72.

9. Menezo JL, Peris-Martinez C, Cisneros-Lanuza AL, MartínezCosta R. Rate of cataract formation in 343 highly myopic eyes after implantation of three types of phakic intraocular lenses. J Refract Surg. 2004;20:317-24.

10. Ruiz-Moreno J, Montero J, de la Vega C, Alió JL, Zapater P. Retinal detachment in myopic eyes after phakic intraocular lens implantation. J Refract Surg. 2006;22:247-52.

11. Al Sabaani N, Al Assiri A, Al Torbak A, Al Motawa S. Outcome of phakic ICL for myopia. Saudi J Ophthalmol. 2013;27:259-66.

12. Alió JL, Pena-Garcia P, Pachkoria K, Alió JL, El Aswad A. Intraocular optical quality of phakic intraocular lenses: comparison of angle-supported, iris-fixated, and posterior chamber lenses. Am J Ophthalmol. 2013;156:789-99.

13. Aerts AA, Jonker SM, Wielders LH, Berendschot TT, Doors M, De Brabander J, et al. Phakic intraocular lens: two-year results and comparison of endothelial cell loss with iris-fixated intraocular lenses. J Cataract Refract Surg. 2015;41:2258-65. https://doi.org/ 10.1016/j.jcrs.2015.10.039.

14. Ferris FL. Kassoff A, Bresnick GH, Bailey I. New visual acuity charts for clinical research. Am J Ophthalmol. 1982;94:91-96.

15. JL Alió, Peña-García P, Abdulla GF, Zein G, Abu-Mustafa SK. Comparison of iris-claw and posterior chamber collagen copolymer phakic intraocular lenses in keratoconus. J Cataract Refract Surg. 2014;40:383-94. https://doi.org/10.1016/j.jcrs.2013. 07.052 .

16. Ghoreishi M, Agherian R, Peyman AR, Feshareki H, Mohammadinia M. Flexible toric iris claw phakic intraocular lens implantation for myopia and astigmatism. J Ophthalmic Vis Res. 2014;9:174-80. PMID: 25279118, PMCID: PMC4181199.

17. Ghoreishi M, Masjedi A, Nasrollahi K, Rahgozar A, Jenab K, Fesharaki H. Artiflex versus STAAR implantable contact lenses for correction of high myopia. Oman $\mathrm{J}$ Ophthalmol. 2011;4:116-9. https://doi.org/10.4103/0974-620X.91266.

18. Doors M, Budo CJ, Christiaans BJ, Luger M, Marinho AA, Dick HB. Artiflex Toric foldable phakic intraocular lens: short term results of a prospective European multicentre study. Am J Ophthalmol. 2012;154:730-9.

19. Nassiri N, Ghorbanhosseini S, Jafarzadehpur E, Kavousnezhad S, Nassiri N, Sheibani K. Visual acuity, endothelial cell density and polymegathismafter iris-fixated lens implantation. Clin Ophthalmol. 2018;12:601-5. https://doi.org/10.2147/OPTH.S157501.

20. Hashemi H, Miraftab M, Asgari S. Comparison of the visual outcomes between PRK-MMC and phakic IOL implantation in high myopic patients. Eye (Lond). 2014;28:1113-8. https://doi. org/10.1038/eye.2014.115.

21. Hashemi H, Taherzadeh M, Khabazkhoob M. Correction of high myopia with foldable Artiflex phakic intraocular lenses: 1-year follow-up results. Acta Med Iran. 2013;51:620-5.

22. Ruckhofer J, Seyeddain O, Dexl AK, Grabner G, Stoiber J. Correction of myopic astigmatism with a foldable iris-claw toric phakic intraocular lens: short-term follow-up. J Cataract Refract Surg. 2012;38:582-8. https://doi.org/10.1016/j.jcrs.2011.11.027.

23. Dick HB, Budo C, Malecaze F, Guell JL, Marinho AA, Nujts RM, et al. Foldable Artiflex phakic intraocular lens for the correction of myopia: two year follow up results of a prospective European multicenter study. Ophthalmology. 2009;116:671-7. https://doi. org/10.1016/j.ophtha.2008.12.059.

24. Coullet J, Gontran E, Fournié P, Arné JL, Malecaze F. Refractive efficacy and tolerance of the foldable phakic iris-supported Artiflex lens in the surgical correction of moderately high myopia: a 2year follow- up. J Fr Ophtalmol. 2007;30:335-43.

25. Muñoz G, Cardoner A, Albarrán-Diego $C$, Ferrer-Blasco $T$, Belda-Salmerón L. Iris-fixated toric phakic intraocular lens for myopic astigmatism. J Cataract Refract Surg. 2012;38:1166-75. https://doi.org/10.1016/j.jcrs.2012.02.034.

26. Albarrán-Diego C, Muñoz G, Ferrer-Blasco T, García-Lázaro S, Belda-Salmerón L. Foldable iris-fixated phakic intraocular lens vs femtosecond laser-assisted LASIK for myopia between -6.00 and -9.00 diopters. J Refract Surg. 2012;28:380-6. https://doi.org/10. 3928/1081597X-20120508-01.

27. Akcay L, Eser I, Kaplan AT, Taskiran-Comez A, Dogan OK. Phakic anterior chamber lenses in very high myopia: an 18-month follow up. Clin Exp Ophthalmol. 2012;40:275-81. https://doi.org/ 10.1111/j.1442-9071.2011.02632.x.

28. Huang D, Schallhorn SC, Sugar A, Farjo AA, Majmudar PA, Trattler WB, et al. Phakic intraocular lens implantation for the correction of myopia: a report by the american academy of ophthalmology. Ophthalmology. 2009;116:2244-58. 